\title{
Relationship between litter produced by Calamagrostis epigejos and seedling recruitment of mesic meadow species in mountain conditions
}

\author{
D. Pruchniewicz ${ }^{1}$ and L. Żołnierz \\ Department of Botany and Plant Ecology, Wroctaw University of Environmental and Life Sciences, \\ pl. Grunwaldzki 24a, PL-50-363 Wrocław, Poland \\ ${ }^{I}$ Corresponding author: Tel.: +48713201588; E-mail: daniel.pruchniewicz@upwr.edu.pl
}

Keywords: Arrhenatheretalia order; Decomposition process; Degradation of vegetation; Environmental factors; Expansive species.

\begin{abstract}
Calamagrostis epigejos produces a large amount of litter in patches dominated by this expansive species in degraded meadows. Two studies were carried out in the area of the Central Sudetes Mountains (SW Poland). The goals of these surveys were to address the following questions: How do active manipulations regarding the removal of necromass and C. epigejos tillers, as well as seeding of additional species, influence the meadow species seedling recruitment? How is the organic matter decomposed in the consecutive stages of mountain grassland degradation caused by C. epigejos expansion? How do environmental factors influence litter decomposition? The results of the research showed a significant influence of C. epigejos necromass on the recruitment of mesic meadow species. The influence is connected with the emergence of a mechanical barrier to seedlings, which impedes their sprouting. No relation was found between the degradation stage and the rate of necromass decomposition. The study showed the influence of some environmental factors on the rate of necromass decomposition - in the case of C. epigejos there was a negative impact of exchangeable magnesium forms, whereas in the case of mixed meadow plant litter there was a positive effect of nitrogen and C:N ratio, and negative correlations with Ellenberg's light and soil humidity indices.
\end{abstract}

Nomeclature: Mirek et al. (2002).

Abbreviations: DCA - Detrended Correspondence Analysis, NMDS - Non-Metric multidimensional analysis, PCA - Principal Components Analysis, $r$ - Pearson correlation coefficient, RDA - Redundancy analysis, Rs - Spearman correlation coefficient, $\mathrm{SD}-$ Standard Deviation.

\section{Introduction}

Mesic meadows belonging to the Arrhenatheretalia order represent habitats important for the cultural landscape of Europe. They occur both in lowlands and in lower altitudes in mountains. These species-rich anthropogenic meadows represent Natura 2000 habitat 6510 . These habitats owe their existence to constant and systematic hay and pasture usage, which shaped their unique species composition and high diversity (Ellenberg 1996). In recent years they have often been abandoned, which causes the process of secondary succession. This problem occurs in particular in the mountain regions of Central Europe (Poschlod et al. 2005, Niedrist et al. 2009, Pruchniewicz 2017). The initiation of ecological succession leads to significant changes in the species composition of meadow communities and changes in their functioning manifesting in changes in water balance and an increase in organic carbon (Holtmeier and Broll 2007, Eldridge et al. 2011). The abandonment of traditional pasture usage strictly connected with defoliation, trampling and manuring also leads to changes in microbiological activity of soils and their biodiversity (Aldezabal et al. 2015). These processes are often accompanied by an increase in standing crop and litter (Jensen and Meyer 2001, Pruchniewicz and Żołnierz 2014).
The decomposition of litter is significant in the case of terrestrial ecosystems because it enables productivity due to the regulation of nutrients available for growing species (Koukoura et al. 2003). The main factors influencing the decomposition process are quality features of litter (Moretto et al. 2001, Ross et al. 2002) and the physico-chemical properties of the environment, which determine species composition and the activity of decomposers (Koukoura 1998). Foster and Gross (1997) suggest that plant litter can directly impact the performance of plants by physically altering environmental conditions, whereas Facelli and Pickett (1991) claim it can influence plants indirectly, by releasing nutrients and phytotoxic substances. The accumulation of litter leads to the creation of an organic layer preventing the germination of seeds and thus restricts seedling recruitment and development. The inhibiting effect of litter accumulation on seedling recruitment was described by Foster (1999) for old-fields, for woodlands by Vellend et al. (2000) and for wet grasslands by Jensen and Meyer (2001). Expanding Calamagrostis epigejos is one of the species producing the highest amounts of litter in the grasslands of Central Europe (Rebele and Lehmann 2001). The expansion of Calamagrostis epigejos in various grassland communities is a phenomenon common to vast areas of Europe (Rebele and Lehmann 2001, Pruchniewicz 2017). This species overcomes meadow communities, creat- 
ing strongly dominated stands by itself. It produces a high standing crop and a thick layer of litter (Pruchniewicz and Żołnierz 2017).

Calamagrostis epigejos is an expansive apophyte distributed widely across Europe and North America (Hultén and Fries 1986, Aiken et al. 1989). In the mountain areas, one can observe vast expansion of C. epigejos in abandoned grasslands within recent years (Pruchniewicz and Żołnierz 2017). C. epigejos shows a set of features allowing it to be a strong competitor in plant communities. It is capable of fast growth and the production of a high standing crop, which leads to the shading of other species (Somodi et al. 2008). Its shoots are avoided by herbivores and, therefore, may create dense stands and eventually a high amount of decomposed necromass (Rebele and Lehmann 2001). However, the competitive mechanisms of C. epigejos influencing meadow vegetation is still relatively poorly known. The process is most likely connected with the production of a thick layer of slowly decomposing litter preventing the germination of seeds (Dolečková and Osbornová 1990, Holub et al. 2004). There are also no data on the rate of decomposition of $C$. epigejos necromass on meadows with different habitat conditions and in various stages of degradation. On the other hand, there is an urgent need to find effective measures to overcome the expansion of $C$. epigejos in meadow areas and to restore their original biodiversity.

Our intention was to verify two hypotheses related to the problem of the influence of litter produced by C. epigejos on seedling recruitment and species composition within meadow patches degraded by the expansion of that species. The first hypothesis is that accumulation of litter decreases the chances of seedling recruitment and thereby affects species diversity and composition. Consequently, we predict that some active measures involving removal of $C$. epigejos litter or both litter and tillers may be used to restrict that effect. The second hypothesis is that environmental factors influence the rate of litter decomposition in meadow patches degraded by C. epigejos.

The field survey encompassed two independent studies concerning phenomena appearing in meadow patches dominated by $C$. epigejos. The first experiment was carried out to determine how $C$. epigejos necromass, as well as some manipulations dealing with it, influences the seedling recruitment and species composition. The second survey was focused on the effect of environmental factors on the process of organic matter decomposition within patches dominated by $C$. epigejos.

In our study we addressed the following questions:

I. How do active manipulations regarding the removal of necromass and $C$. epigejos tillers, as well as seeding of additional species, influence the meadow species seedling recruitment and composition?

II. How do the environmental factors influence the rate of organic matter decomposition in the consecutive stages of mountain grassland degradation?

\section{Material and methods}

The influence of C. epigejos necromass on seedling recruitment and species composition (experiment one)

The experiment was carried out in the Central Sudetes (SW Poland). A meadow degraded as a result of $C$. epigejos expansion (mean cover $80 \%$ in degraded patches and $6 \mathrm{~cm}$ litter accumulated by this species) at the altitude of around $750 \mathrm{~m}$ a.s.l. was selected for the study. In order to determine the influence of $C$. epigejos necromass on seedling recruitment, 5 random blocks were established. Each block consisted of 5 treatments: control (A), necromass removal (B), necromass removal followed by the introduction of 20 Trifolium repens and 20 Rumex acetosa seeds (C), Calamagrostis epigejos necromass and tillers removal from the depth of $0-5 \mathrm{~cm}$ without soil removal (D), necromass and tillers removal from the depth of $0-5 \mathrm{~cm}$ without soil removal and the introduction of 20 Trifolium repens and 20 Rumex acetosa seeds (E). Each treatment was established on a $1 \mathrm{~m}^{2}$ plot. Relevés were sampled from all plots at the beginning of the experiment. Another set of relevés was sampled after 12 months to determine the changes in vegetation.

\section{The effect of environmental factors on the organic matter decomposition within the various stages of mountain meadow degradation caused by C. epigejos expansion (experiment two)}

The study was carried out in the Central Sudetes, including the areas of the Sowie Mountains and hills and valleys south-west of them. Five mesic meadows were selected for the study. The meadows had patches of vegetation degraded and not degraded by C. epigejos expansion. "Litterbags" were used to ascertain the rate of $C$. epigejos necromass decomposition. The bags were flat packages $(15 \mathrm{~cm} \times 10 \mathrm{~cm})$ made of polyethylene net with mesh diameter of $1 \mathrm{~mm}$. Inside there was $3 \mathrm{~g}$ dry mass of plant material belonging to one of two types: $1-$ mixed plant litter: dry shoot biomass of other plants from nondegraded mesic mountain meadows (Arrhenatherum elatius $25 \%$, Agrostis capillaris 20\%, Festuca rubra 20\%, Dactylis glomerata 10\%, Trifolium repens 10\%, Lotus corniculatus $10 \%$, Rumex acetosa $5 \%$ ); and 2 - above-ground parts of $C$. epigejos $(100 \%)$. In the positions established randomly in $C$. epigejos patches within meadows differing in environmental conditions (altitude, exposure, inclination, $\mathrm{pH}$, organic matter, $\mathrm{N}, \mathrm{P}, \mathrm{K}, \mathrm{Ca}, \mathrm{Mg}$ ) the various stages of mesic meadow degradation by $C$. epigejos were defined as follows: the initial stage, $1 \mathrm{~m}$ inside of the border line of the C. epigejos patch (stage I), the advanced stage, $5 \mathrm{~m}$ deep into the $C$. epigejos patch (stage II), and the control (C), set up in a non-degraded part of the meadow $5 \mathrm{~m}$ from the edge of the $C$. epigejos patch.

\section{Chemical analyses}

The soil samples were collected randomly within the studied meadows using a $15 \mathrm{~cm}$ high metal cylinder of 8 
$\mathrm{cm}$ diameter. The samples were later dried at room temperature and, after constant mass was obtained, they were sifted through a sieve with $2 \mathrm{~mm}$ mesh. Afterwards, the following characteristics of the samples were measured: $\mathrm{pH}$ in water; organic matter contents after igniting soil in a muffle furnace at $600^{\circ} \mathrm{C}$; organic carbon, total nitrogen content using the Kjeldahl method; soluble forms of potassium, calcium and magnesium were extracted with $1 \mathrm{M}$ of ammonium acetate pH 7. A Varian SpectrAA 200 spectrometer was used for the determinations of those metals. It was set in the emission measurement mode for potassium and calcium and in the atomic absorption mode for magnesium. Exchangeable forms of phosphorus were determined colorimetrically after extraction in 0.5 M sodium bicarbonate (Allen 1989, Radojević and Bashkin 2006).

\section{Statistical analyses}

In experiment 1 we determined the influence of selected treatment on the species number (s), diversity index (H') and evenness $(\mathrm{J})$. The analysis of variance with Fisher's test was used for variables with a normal distribution, and variance homogeneity or Friedman's rank test for variables without a normal distribution. Wilcoxon's paired signed-rank test was used to determine the diversity parameters between two years of research.

In experiment 2 , in order to determine the rate of dead organic matter decomposition on meadows representing various stages of C. epigejos expansion, we used the analysis of variance with Fisher's test for data with a normal distribution, and variance homogeneity or the Kruskal-Wallis test for data without a normal distribution. Spearman's correlations were used to analyze the relationship between biomass decomposition rate and C. epigejos cover, its above-ground or underground biomass or the species diversity index.

In order to determine the influence of habitat conditions on the rate of dead organic matter decomposition, multiple regression analysis was conducted. A model was constructed using stepwise progressive analysis. All statistical analyses were conducted using STATISTICA v. 12 software (StatSoft Inc. 2014). We tested normality using the Shapiro-Wilk test. The variables for which a normal distribution was obtained were studied with parametric methods: Pearson correlation coefficient, Student's t-test and analysis of variance with Fisher test. Levene's test was used to check for homogeneity of variances. The data for which a normal distribution was not found and/or the assumption of variance homogeneity was not met were tested using non-parametric methods: Spearman correlation (Rs), Wilcoxon signed rank test for paired data, Friedman's rank test or the Kruskal-Wallis test.

In order to compare the species composition for plots before removing the necromass and 12 months after the start of the experiment, principal components analysis (PCA) rotation of non-metric multidimensional scaling (NMDS) was used with Bray-Curtis distance with a 3-dimensional final solution obtained after 42 iterations.
Table 1. Mean values with standard errors of species number $(\mathrm{s})$, diversity index ( $\left.\mathrm{H}^{\prime}\right)$, evenness $(\mathrm{J})$ in 5 studied treatments. Superscripts (a-c) were used to mark homogeneous groups obtained in Fisher's HSD and Friedman's rank test at $\mathrm{p} \leq 0.05$; subscripts $(\mathrm{x}, \mathrm{y})$ were used to indicate the differences between 2015 and 2016 obtained in Wilcoxon's test; Treatments: A - control, $\mathrm{B}$ - removal of the necromass, $\mathrm{C}$ - removal of the necromass and sowing of Trifolium repens and Rumex acetosa, D - removal of the necromass and tillers of Calamagrostis epigejos, E - sowing of $T$. repens and $R$. acetosa after removal of the necromass and C. epigejos tillers.

\begin{tabular}{|c|c|c|}
\hline Treatment & 2015 & 2016 \\
\hline & \multicolumn{2}{|c|}{ Number of species (s) } \\
\hline A & $3.80 \pm 0.58_{\mathrm{x}}^{\mathrm{a}}$ & $4.00 \pm 0.45_{\mathrm{x}}^{\mathrm{abc}}$ \\
\hline B & $3.60 \pm 0.40_{x^{a}}$ & $3.60 \pm 0.60_{\mathrm{x}}^{\mathrm{ab}}$ \\
\hline $\mathrm{C}$ & $3.60 \pm 0.24_{\mathrm{x}}^{\mathrm{a}}$ & $5.00 \pm 0.45_{\mathrm{x}} \mathrm{bc}$ \\
\hline $\mathrm{D}$ & $3.20 \pm 0.37 \mathrm{x}$ & $3.20 \pm 0.49_{\mathrm{x}}^{\mathrm{a}}$ \\
\hline \multirow[t]{2}{*}{$\mathrm{E}$} & $3.80 \pm 0.58_{\mathrm{x}}^{\mathrm{a}}$ & $5.20 \pm 0.49 \mathrm{y}^{\mathrm{c}}$ \\
\hline & \multicolumn{2}{|c|}{ Diversity index $\left(\mathrm{H}^{\prime}\right)$} \\
\hline A & $0.58 \pm 0.12_{\mathrm{x}}^{\mathrm{a}}$ & $0.79 \pm 0.09_{x}^{a}$ \\
\hline B & $0.35 \pm 0.08_{\mathrm{x}}^{\mathrm{a}}$ & $0.62 \pm 0.13_{\mathrm{y}}^{\mathrm{a}}$ \\
\hline $\mathrm{C}$ & $0.39 \pm 0.10_{\mathrm{x}^{\mathrm{a}}}$ & $0.63 \pm 0.06_{\mathrm{y}^{\mathrm{a}}}$ \\
\hline $\mathrm{D}$ & $0.38 \pm 0.09_{\mathrm{x}}^{\mathrm{a}}$ & $0.62 \pm 0.12_{\mathrm{x}}^{\mathrm{a}}$ \\
\hline \multirow[t]{2}{*}{$\mathrm{E}$} & $0.39 \pm 0.11_{\mathrm{x}}^{\mathrm{a}}$ & $0.65 \pm 0.13_{\mathrm{x}}^{\mathrm{a}}$ \\
\hline & \multicolumn{2}{|c|}{ Evenness index ('J) } \\
\hline A & $0.44 \pm 0.07 \mathrm{x}^{\mathrm{a}}$ & $0.58 \pm 0.04_{\mathrm{x}}^{\mathrm{a}}$ \\
\hline B & $0.29 \pm 0.07 \mathrm{x}^{\mathrm{a}}$ & $0.49 \pm 0.06_{\mathrm{y}}^{\mathrm{a}}$ \\
\hline $\mathrm{C}$ & $0.30 \pm 0.06_{\mathrm{x}}^{\mathrm{a}}$ & $0.40 \pm 0.05_{\mathrm{x}}^{\mathrm{a}}$ \\
\hline $\mathrm{D}$ & $0.34 \pm 0.06_{\mathrm{x}}^{\mathrm{a}}$ & $0.56 \pm 0.10_{\mathrm{x}}^{\mathrm{a}}$ \\
\hline $\mathrm{E}$ & $0.30 \pm 0.099_{\mathrm{x}}^{\mathrm{a}}$ & $0.39 \pm 0.05_{\mathrm{x}}^{\mathrm{a}}$ \\
\hline
\end{tabular}

To reveal the main environmental gradients on the basis of the species composition of vegetation, detrended correspondence analysis (DCA) was conducted. The length of the gradient represented by the first DCA canonical axis was 2.4 $\mathrm{SD}$; therefore to determine the influence of the studied treatments on vegetation RDA analysis was used. The significance of the variables was tested with the Monte Carlo permutation test with stepwise variable selection. The calculations were done only for data representing 12 months after the start of the experiment. All ordination analyses were performed using the CANOCO v. 5.03 software (ter Braak and Šmilauer 2012).

Species diversity was assessed by the number of species and diversity indices. The Shannon-Wiener diversity index was calculated according to the formula: $H^{\prime}=-\Sigma\left(p_{i} \ln p_{i}\right)$, and the evenness index was calculated as follows: $\mathrm{J}^{\prime}=\mathrm{H}^{\prime} / \mathrm{ln}$ $\mathrm{S}$, where $\mathrm{p}_{\mathrm{i}}=\mathrm{n}_{\mathrm{i}} / \mathrm{N} ; \mathrm{n}_{\mathrm{i}}=$ the abundance of the species expressed as its cover; $\mathrm{N}=$ the sum of abundances of all species, and $\mathrm{S}$ $=$ the total number of species. The MVSP v. 3.131 package (Kovach Computing Services 2004) was used for calculating all diversity indices.

Mean Ellenberg's indicator values weighted by the species cover were counted for vegetation of the studied plots (Ellenberg et al. 1992). 


\section{Results}

The influence of C. epigejos necromass on seedling recruitment and species composition (experiment one)

The obtained results show the significant influence of necromass removal on biodiversity indices at 12 months after the beginning of the experiment (Table 1). In the case of treatment B - necromass removal, diversity index and evenness index increased twofold. Similar results were obtained in the case of necromass removal with the introduction of test species (treatment C), and the influence was solely on diversity index. In the case of the last treatment - necromass and tillers removal with the introduction of Trifolium repens and Rumex acetosa (treatment E), a significant increase in the number of
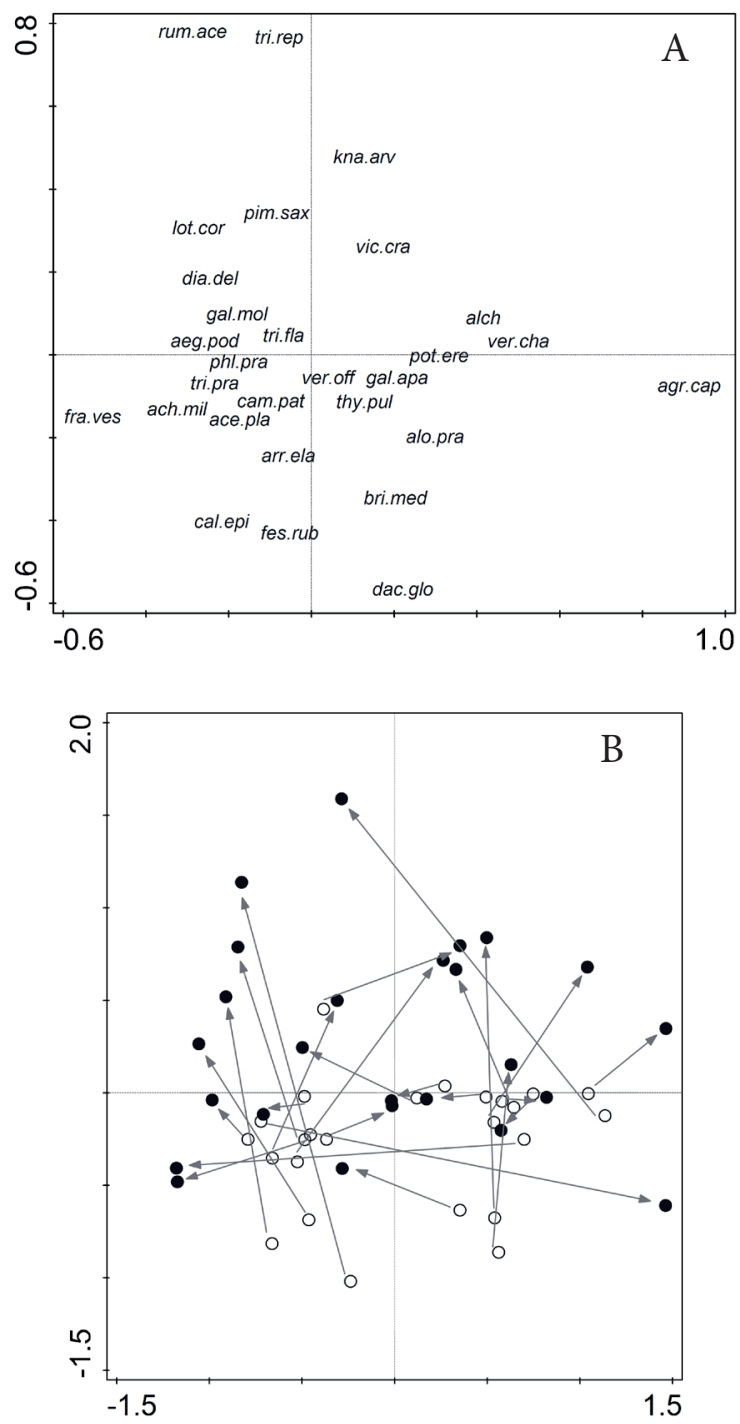

Figure 1. Principal components analysis rotation of non-metric multidimensional scaling ordination diagrams for species (A) and sites (B) before removal of necromass (empty circles) and 12 months after the start of the experiment (filled circles). Plant names' abbreviations represent the first three letters of the genus and species. A species list is presented in Table 2. species was recorded. No significant differences were noted for other treatments.

The comparison of diversity indices for all experimental treatments (Table 1) indicates that the highest number of species was noted on plots were the necromass and tillers of $C$. epigejos were removed and $T$. repens and $R$. acetosa were sown (treatment $\mathrm{E}: \mathrm{F}=3.064 ; \mathrm{p}=0.040$ ).

In the principal components analysis rotation of nonmetric multidimensional scaling the eigenvalues for the first two axes were 0.4898 and 0.2722 respectively. The cumulative values of the explained variance of species data for those axes were 48.98 and 76.21 respectively. The stress level was $14.7 \%$, which indicated good quality of the obtained model. Fig. 1 shows species and respective sites in two referenced years. Using treatments with necromass and tillers removal and the sowing of test species resulted in significant changes in the studied plots. The process is particularly visible in the case of typical meadow species, which, as a result of mechanical necromass removal, returned to plots dominated previously by C. epigejos.

In the case of treatment B the study revealed a higher cover of Agrostis capillaris, Alopecurus pratensis, Arrhenatherum elatius and Trisetum flavescens with simultaneous decrease of cover of Aegopodium podagraria, Calamagrostis epigejos, Festuca rubra and Phleum pratense. In the case of treatment C the study revealed a decreased cover of Acer platanoides saplings, Agrostis capillaris, C. epigejos, Dactylis glomerata, Festuca rubra, Potentilla erecta and Veronica chamaedrys with an increase of Arrhenatherum elatius, Fragaria vesca, Knautia arvensis, Lotus corniculatus, Phleum pratense, Rumex acetosa, Thymus pulegioides and Trifolium repens. In treatment D cover was decreased for Agrostis capillaris, Briza media, C. epigejos, Festuca rubra and Trifolum pratense with an increase in Arrhenatherum elatius, Fragaria vesca, Galium mollugo, Phleum pratense and Trisetum flavescens. In the last treatment, $\mathrm{E}$, decrease was observed for Agrostis capillaris, Arrhenatherum elatius, Briza media, $C$. epigejos, Dactylis glomerata, Festuca rubra and Phleum pratense, while increase for Dianthus deltoides, Fragaria vesca, Knautia arvensis, Lotus corniculatus, Pimpinella saxifraga, Rumex acetosa, Trisetum flavescens and Vicia cracca (Table 2). What is important is the decrease in C. epigejos cover in all studied treatments. Considering the number of species changing their cover, the biggest changes occurred in treatments $\mathrm{C}$ and $\mathrm{E}$ ( 7 species), treatment D (5 species) and treatment B (4 species).

RDA was used to determine the influence of the studied treatments on species composition. Calculations were conducted for data from only 2016. Monte Carlo test results and stepwise variable selection determined a significant influence of two experimental treatments on the vegetation of the study plots (Table 3): $\mathrm{C}$ - the removal of necromass from 0-5 $\mathrm{cm}$ and the introduction of 20 Trifolium repens and Rumex acetosa seeds; and $\mathrm{E}$ - the removal of necromass and tillers from $0-5 \mathrm{~cm}$ with the introduction of 20 Trifolium repens and Rumex acetosa seeds. 
Table 2. Mean species cover within the studied blocks expressed on percentage scale. A, A1 (control); B, B1, etc. - refer to treatments at the start and completion of the experiment, respectively. $\Delta$ - difference in the mean cover between years 2015 and 2016, - Lack of the species.

\begin{tabular}{|c|c|c|c|c|c|c|c|c|c|c|c|c|c|c|c|c|}
\hline & & $\mathrm{A}$ & $\mathrm{A} 1$ & $\Delta_{\mathrm{A}}$ & B & B1 & $\Delta_{\mathrm{B}}$ & $\mathrm{C}$ & $\mathrm{C} 1$ & $\Delta_{\mathrm{C}}$ & $\mathrm{D}$ & D1 & $\Delta_{\mathrm{D}}$ & $\mathrm{E}$ & E1 & $\Delta_{\mathrm{E}}$ \\
\hline Acer platanoides & ace.pla & 3.0 & - & -3.0 & - & - & 0.0 & 1.0 & - & -1.0 & - & - & 0.0 & - & - & 0.0 \\
\hline chillea millefolium & ac & 4 & 5.0 & 0 & - & - & 0.0 & - & - & 0.0 & - & - & 0.0 & & - & 0.0 \\
\hline gopodium podagraria & aeg.pod & 5 & - & 5.0 & 1.0 & - & -1.0 & - & - & 0.0 & - & - & 0.0 & - & - & 0.0 \\
\hline s capillaris & ag & 12.8 & 13.3 & 0.6 & 15.0 & 21.8 & 6.8 & 10.0 & 3.5 & -6.5 & 13.8 & 5.0 & -8.8 & 15.0 & 6.7 & -8.3 \\
\hline lchemilla $s p$ & & & - & -7.0 & - & - & 0.0 & - & - & 0.0 & - & - & 0.0 & - & - & 0.0 \\
\hline ratensis & al & & - & -8.0 & - & 2.0 & 2.0 & - & - & 0.0 & - & - & 0.0 & & - & 0.0 \\
\hline & arr.e & & - & -5.0 & 1.0 & 5.0 & 4.0 & - & 1.0 & 1.0 & - & 5.0 & 5.0 & 3.0 & - & -3.0 \\
\hline & b & 10.0 & - & 0.0 & - & - & 0.0 & - & - & 0.0 & 1.0 & - & -1.0 & 0 & - & -1.0 \\
\hline Cal & $\mathrm{c}$ & 62.2 & 57.5 & -4.7 & 80.0 & 64.0 & -16.0 & 80.0 & 60.0 & -20.0 & 83.0 & 45.0 & -38.0 & 74.0 & 57.0 & -17.0 \\
\hline & cam. & & 5.0 & -7.0 & - & - & & - & - & $\mathbf{0 . 0}$ & - & - & 0.0 & - & - & 0.0 \\
\hline & d & 11.5 & - & 11.5 & 5.0 & 5.0 & & 2.3 & - & -2.3 & - & - & 0.0 & 3.5 & - & -3.5 \\
\hline 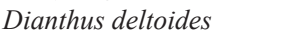 & & 14. & - & 14.0 & - & - & & - & - & 0.0 & - & - & 0.0 & - & 5.0 & 5.0 \\
\hline & f & & - & -8.0 & 1.0 & - & -1.0 & 3.0 & 1.0 & -2.0 & 1.0 & - & -1.0 & 1.0 & - & -1.0 \\
\hline & f & & 4.0 & -4.5 & 5.0 & 5.0 & & 3.7 & 6.3 & 2.7 & 1.0 & 3.7 & 2.7 & - & 1.0 & 1.0 \\
\hline & & & 1.0 & -16.0 & - & - & & - & - & 0.0 & - & - & 0.0 & - & - & 0.0 \\
\hline ugo & $\mathrm{g}$ & & - & 8.0 & - & - & & - & - & 0.0 & - & 5.0 & 5.0 & - & - & 0.0 \\
\hline & & & - & 9.0 & 1.0 & 1.0 & & - & 10.0 & 10.0 & - & - & 0.0 & 1.0 & 5.0 & 4.0 \\
\hline thy & & & - & 0.0 & - & - & & - & - & 0.0 & - & - & 0.0 & - & - & 0.0 \\
\hline & & & - & 1.0 & - & - & & - & 5.0 & .0 & - & - & 0.0 & - & 5.0 & 5.0 \\
\hline & & & - & 1.5 & 1.0 & - & -1.0 & 1.0 & 5.0 & 4.0 & 1.0 & 8.0 & 7.0 & 1.0 & - & -1.0 \\
\hline Pim & $\mathrm{p}$ & & - & 3.0 & - & - & 0. & - & - & .0 & - & - & 0.0 & - & 5.0 & 5.0 \\
\hline & & & - & -24.0 & - & - & & 5.0 & - & -5.0 & - & - & 0.0 & - & - & 0.0 \\
\hline & rum. & & - & -25.0 & - & - & & - & 1.0 & 1.0 & - & - & 0.0 & - & 1.0 & 1.0 \\
\hline & & 15 & 10.0 & -5.5 & 1.0 & 1.0 & & - & 1.0 & .0 & - & - & 0.0 & - & - & 0.0 \\
\hline & & 27.0 & - & -27.0 & - & - & 0 & - & 1.0 & 1.0 & - & - & 0.0 & 1.0 & 1.0 & 0.0 \\
\hline & & & - & -28.0 & - & - & & - & - & 0.0 & 2.0 & - & -2.0 & - & - & 0.0 \\
\hline Trisetum flavescens & & & - & -29.0 & - & 5.0 & & - & - & 0.0 & - & 1.0 & 1.0 & - & 2.0 & 2.0 \\
\hline Veronica chamaedrys & ver.cha & 15.5 & - & -15.5 & - & - & 0.1 & 5.0 & - & -5.0 & - & - & 0.0 & - & - & 0.0 \\
\hline Veronica officinalis & ver.off & 31.0 & 1.0 & -30.0 & - & - & 0.0 & - & - & 0.0 & - & - & 0.0 & - & - & 0.0 \\
\hline Vicia cracca & vic.cra & 32.0 & - & -32.0 & - & & 0.0 & - & - & 0.0 & - & - & 0.0 & - & 1.0 & 1.0 \\
\hline
\end{tabular}
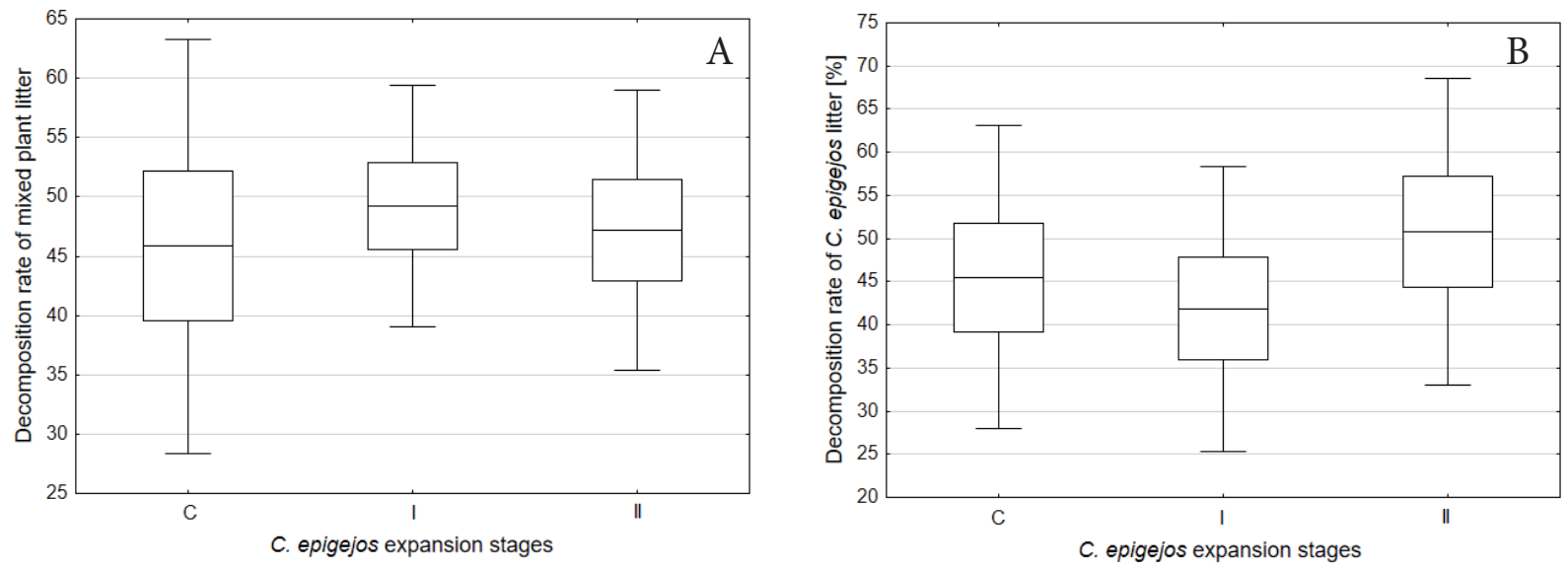

Figure 2. Decomposition rate of mixed plant litter (A) and of Calamagrostis epigejos (B) in the consecutive stages of C. epigejos expansion: patches without C. epigejos (Control), initial (I), and advanced (II). The figures show means, standard errors (boxes) and $95 \%$ confidence intervals (whiskers).

The effect of environmental factors on the organic matter decomposition within the various stages of mountain meadow degradation caused by C. epigejos expansion (experiment two)

Statistical analysis did not indicate any significant differences in Calamagrostis epigejos necromass decomposition rate $(H=0.980 ; p=0.612)$ or mixed plant litter $(F=0.122 ; p$ $=0.885)$ in non-degraded grasslands or in those representing initial or advanced degradation stages (Fig. 2). Additionally, no significant differences were found in decomposition rate between Calamagrostis epigejos litter and mixed plant material. 
Table 3. Forward variable selection results for the RDA analysis..

\begin{tabular}{ccccc}
\hline Treatment & $\begin{array}{c}\text { Explained } \\
\text { variance } \%\end{array}$ & $\begin{array}{c}\text { Contribution } \\
\%\end{array}$ & pseudo-F & P \\
\hline E & 8.9 & 32.5 & 2.3 & 0.018 \\
C & 10.5 & 38.3 & 2.9 & 0.012 \\
\hline
\end{tabular}

Table 4. Summary of the multiple regression analysis for the dependent variable "the rate of $C$. epigejos litter decomposition." $\mathrm{R}$ $=0.88, \mathrm{R}^{2}=0.78$, adjusted $\mathrm{R}^{2}=0.66, \mathrm{~F}=6.48, \mathrm{p}=0.008$, standard error of estimation: 7.81

\begin{tabular}{|c|c|c|c|c|c|c|}
\hline & Beta 1 & $\begin{array}{c}\text { Standard } \\
\text { error } 1\end{array}$ & Beta 2 & $\begin{array}{c}\text { Standard } \\
\text { error } 2\end{array}$ & $\mathrm{t}$ & $\mathrm{p}$ \\
\hline Intercept & & & 452.034 & 137.782 & 3.281 & 0.010 \\
\hline $\mathrm{Mg}$ & -0.966 & 0.178 & -0.310 & 0.057 & -5.424 & 0.000 \\
\hline
\end{tabular}

Table 5. Summary of multiple regression analysis for the dependent variable "the rate of mesic meadow mixed plant material decomposition". $\mathrm{R}=0.93, \mathrm{R} 2=0.86$, adjusted $\mathrm{R}^{2}=0.73, \mathrm{~F}=6.31$, $p=0.01$, standard error of estimation: 5.33. Abbreviations: L_Ell and F_Ell - Ellenberg's indicator values for light and soil humidity respectively.

\begin{tabular}{lcccccc}
\hline & Beta 1 & $\begin{array}{c}\text { Standard } \\
\text { error 1 }\end{array}$ & Beta 2 & $\begin{array}{c}\text { Standard } \\
\text { error 2 }\end{array}$ & $\mathrm{t}$ & $\mathrm{p}$ \\
\hline Intercept & & & 180.522 & 47.378 & 3.810 & 0.007 \\
L_Ell & -0.650 & 0.257 & -11.469 & 4.533 & -2.530 & 0.039 \\
C:N & 1.506 & 0.520 & 3.910 & 1.349 & 2.899 & 0.023 \\
F_Ell & -0.747 & 0.257 & -21.743 & 7.482 & -2.906 & 0.023 \\
N & 1.383 & 0.566 & 176.351 & 72.175 & 2.443 & 0.045 \\
\hline
\end{tabular}

No significant correlations were found between the studied biomass decomposition rate and C. epigejos cover, its aboveground or under-ground biomass or species diversity index.

Multiple stepwise regression analyses were used to determine the influence of environmental factors on the litter decomposition rate. In the case of C. epigejos litter, the final model was obtained in the fifth step of the analysis (Table $4)$. The results of the analysis along with the calculated coefficients of partial correlation showed a negative correlation between $C$. epigejos dead biomass decomposition rate and the concentrations of exchangeable magnesium forms $(\mathrm{r}=$ $-0.875 ; p=0.0004)$. In the case of mixed meadow plant litter the final model was obtained in the seventh step of the analysis (Table 5). The results showed negative correlations with Ellenberg's indicator value for soil humidity $(\mathrm{Rs}=-0.739$; $\mathrm{p}=0.023)$ and Ellenberg's light indicator $(\mathrm{Rs}=-0.691 ; \mathrm{p}=$ $0.039)$ and positive correlations with $\mathrm{C}: \mathrm{N}$ ratio $(\mathrm{Rs}=0.739 ; \mathrm{p}$ $=0.023)$ and nitrogen $(\mathrm{Rs}=0.678 ; \mathrm{p}=0.045)$.

\section{Discussion}

The influence of C. epigejos necromass on seedling recruitment and species composition (experiment one)

The results of the studies showed a significant impact of some treatments on the composition and diversity of the studied grasslands - the removal of necromass with the sowing of grassland species and the removal of $C$. epigejos necromass and tillers along with the introduction of Trifolium repens and Rumex acetosa (the treatment with the highest diversity). Previous studies showed an impeding influence of $C$. epigejos necromass on the species diversity and productivity of mountain grassland habitats (Pruchniewicz and Żołnierz 2017). The negative impact of litter may be connected with its diverse mechanisms of influence. The first one consists in creating a mechanical barrier preventing the germination and growth of seedlings (Donath and Eckstein 2008). The second mechanism is related to changes in soil humidity or light availability (Holmgren et al. 1997). The third mechanism consists in the secretion of allelochemicals from decomposing necromass which inhibits the growth of other species (Ruprecht et al. 2008, Loydi et al. 2015). Still, previous laboratory studies of the allelopathic potential of $C$. epigejos did not show any strong correlation between $C$. epigejos necromass solutions and an impediment of terrestrial species growth (Pruchniewicz and Halarewicz, unpublished). Among the studied meadow species only Festuca pratensis showed a strong necromass phytotoxic effect. In the cases of other species, e.g., Rumex acetosa, it was impossible to unambiguously confirm the inhibiting influence of allelochemicals from C. epigejos necromass. The results presented in this paper indicate the lack of allelopathic influence of $C$. epigejos necromass on the germination and growth of meadow species. The two test taxa-Trifolium repens and Rumex acetosa - showed increased germination, which suggests that the hypothesis of $C$. epigejos necromass allelopathic influence may be discarded.

Despite numerous articles indicating a negative impact of litter on vegetation, it is possible to find literature showing a slight positive impact on species, which may be connected with, among other factors, fertilization of the ground (Foster and Gross 1997, Donath and Eckstein 2008). Previous research conducted in mesic meadows degraded by C. epigejos showed positive correlations between the amount of necromass and an increase in the soil's phosphorus and potassium (Pruchniewicz and Żołnierz 2017). However, the stimulating fertilization effect seemed to be inhibited by another mechanism, probably connected with mechanical difficulties in germination. With small amounts of litter even some plant growth stimulation may be observed through influencing the physical properties of habitats, e.g., temperature or soil humidity (Eckstein and Donath 2005, Deutsch et al. 2010). Still, large amounts of litter may have an inhibiting effect (Xiong and Nilsson 1999). Research conducted by Jensen and Gutekunst (2003) recorded a positive relation between seed mass and the ratio of species germinating in darkness, and seedling establishments situated $3 \mathrm{~cm}$ under a layer of litter. The size of plant necromass on surfaces degraded by C. epigejos often exceeds the thickness of $6 \mathrm{~cm}$. Additionally, that litter decomposes very slowly (Dolečková and Osbornová 1990, Holub et al. 2004). Therefore, it could be concluded that the negative impact of $C$. epigejos and its necromass may be connected with the creation of a thick mechanical barrier preventing seed germination and seedling recruitment. 
The effect of environmental factors on the organic matter decomposition within the various stages of mountain meadow degradation caused by C. epigejos expansion (experiment two)

The study results did not show any significant differences in $C$. epigejos biomass or mixed plant litter decomposition rate between non-degraded grasslands and those in the initial and advanced stages of degradation. The lack of differences in decomposition rate may be connected with the disturbance in carbon circulation. Slowly decomposing litter leads to lower amounts of carbon reaching the soil, and, consequently, influences the activity of microorganisms responsible for decomposition (Knapp et al. 1998, Sankaran and Augustine 2004). This phenomenon may occur in the case of non-degraded meadows. Mowing with the removal of mowed biomass also influences the amount of carbon available to microorganisms (Knapp et al. 1998, Sankaran and Augustine 2004), which is reflected in the plant material decomposition rate. It should be noted that there were no differences in the decomposition rate between the degraded and non-degraded meadows, which suggests that $C$. epigejos expansion does not influence the activity of soil microorganisms.

While determining the habitat's influence on the studied biomass decomposition rate, the results of the survey also showed a significant negative correlation between decomposition rate and concentrations of exchangeable magnesium forms. In the case of grassland biomass, there were negative correlations with Ellenberg's humidity and light indices with a stimulating effect of soil $\mathrm{C}: \mathrm{N}$ ratio and total nitrogen content. The negative impact of light on the decomposition rate is explained by changes in the chemical characteristics of litter and the composition of microbial communities (Almagro et al. 2015 among others), which may be supported by the results of this study.

In their studies, Herold et al. (2014) claim that microorganism and enzyme activity is stimulated by an increased Ellenberg's humidity index. The results presented in this paper contradict this. In the case of the studied grassland habitats there was a negative correlation between decomposition rate and soil humidity index.

The time needed for organic matter to decompose also depends on its chemical composition expressed as the C:N ratio (Mellilo et al. 1982). Koukoura et al. (2003) observed increased nitrogen, potassium and calcium contents in the soil during the decomposition process, which influenced the activity of soil microorganisms. The results in this paper correspond with the research of Hooper et al. (2005). The authors found that decreased nitrogen content in soil may cause inhibition of the decomposition process. The results correspond with the results of this study, which suggest significant positive correlations between nitrogen and carbon concentrations, and dead organic matter decomposition rate.

\section{Conclusion}

The results presented in this paper show a significant influence of $C$. epigejos necromass on the recruitment of species characteristic of mesic meadows. The influence of $C$. epigejos necromass is connected with the emergence of a mechanical barrier to seedlings, which impacts their growth and development. No relation was found between the degree of C. epigejos expansion and the rate of litter decomposition. In this case there may be a correlation between mesic meadow vegetation degradation and decreased microorganism activity. There is, however, a strong correlation between some environmental factors and organic matter decomposition rate expressing indirect microorganism activity.

\section{References}

Aiken, S.G., L.P. Lefkovitch, and K.C. Armstrong. 1989. Calamagrostis epigejos (Poaceae) in North America, especially Ontario. Can. J. Bot. 67:3205-3218.

Aldezabal, A., L. Moragues, I. Odriozola and I. Mijangos. 2015. Impact of grazing abandonment on plant and soil microbial communities in an Atlantic mountain grassland. Appl. Soil Ecol. 96:251-260.

Almagro, N., F.F. Maestre, J. Martínez-López, E. Valencia and A. Rey. 2015. Climate change may reduce litter decomposition while enhancing the contribution of photodegradation in dry perennial Mediterranean grasslands. Soil Biol. Biochem. 90:214 223.

Allen, S. E. (Ed.) 1989. Chemical Analysis of Ecological Materials. Second edition completely revised. Blackwell. Oxford.

Deutsch, E.S., E.W. Bork and W.D. Willms. 2010. Separation of grassland litter and ecosite influences on seasonal soil moisture and plant growth dynamics. Plant Ecol. 209:135-145.

Dolečková, H. and J. Osbornová, 1990. Competition ability and plasticity of Calamagrostis epigejos. Zpr Čs. Bot. Společ. 25:35-38.

Donath, T.W. and R.L. Eckstein. 2008. Grass and oak litter exert different effects on seedling emergence of herbaceous perennials from grasslands and woodlands. J. Ecol. 96:272-280.

Eckstein, R.L. and T.W. Donath. 2005. Interactions between litter and water availability affect seedling emergence in four familial pairs of floodplain species. J. Ecol. 93:807-816.

Eldridge, D.J., M.A. Bowker, F.T. Maestre, E. Roger, J.F. Reynolds, and W.G. Whitford. 2011. Impacts of shrub encroachment on ecosystem structure and functioning: towards a global synthesis. Ecol. Lett. 14:709-722.

Ellenberg, H., H. Weber, R. Düll, V. Wirth, W. Werner, and D. Paulißen. 1992. Zeigerwerte von Pflanzen in Mitteleuropa. Scripta Geobotanica, vol 18, 2nd edn. Verlag Erich Goltze KG, Göttingen. (in German)

Ellenberg, H. 1996. Vegetation Mitteleuropas mit den Alpen. 5. Auflage. Ulmer, Stuttgart.

Facelli, J. M. and S. T. A. Pickett. 1991. Plant litter: Its dynamics and effects on plant community structure. Bot. Rev. 57:1-32.

Foster, B.L. 1999. Establishment, competition and the distribution of native grasses among Michigan old-fields. J. Ecol. 87:476-489.

Foster, B.L. and K.L. Gross. 1997. Partitioning the effects of plant biomass and litter on Andropogon gerardi in old-field vegetation. Ecology 78:2091-2104. 
Herold, N., I. Schöning, J. Gutknecht, F. Alt, S. Boch, J. Müller, Y. Oelmann, S.A. Socher, W. Wilcke, T. Wubet and M. Schrumpf. 2014. Soil property and management effects on grassland microbial communities across a latitudinal gradient in Germany. Appl. Soil Ecol. 73:41-50.

Holmgren, M., M. Scheffer and M.A. Huston. 1997. The interplay of facilitation and competition in plant communities. Ecology 78:1966-1975.

Holtmeier, F.K. and G. Broll. 2007. Treeline advance - driving processes and adverse factors. Landsc. Online 1:1-33.

Holub, P., I. Sedláková, K. Fiala, I. Tůma, J. Záhora and M. Tesařová. 2004. Reasons and consequences of expansion of Calamagrostis epigejos in meadows of the Dyje river floodplain. Verhandlungen der Gesellschaft für Ökologie 34:167.

Hooper, D.U., F.S. Chapin, J.J. Ewel, A. Hector, P. Inchausti, S. Lavorel, J.H,. Lawton, D.M. Lodge, M. Loreau, S. Naeem, B. Schmid, H. Setala, A.J. Symstad, J. Vandermeer and D.A. Wardle. 2005. Effects of biodiversity on ecosystem functioning: a consensus of current knowledge. Ecol. Monogr. 75:3-35.

Hultén, E. and M. Fries. 1986. Atlas of North European Vascular Plants. North of the Tropic of Cancer. Koeltz Scientific Books.

Jensen, K. and K. Gutekunst. 2003. Effects of litter on establishment of grassland plant species: the role of seed size and successional status. Basic Appl. Ecol. 4:579-587.

Jensen, K. and C. Meyer. 2001. Effects of light competition and litter on the performance of Viola palustris and on species composition and diversity of an abandoned fen grassland. Plant Ecol. 155:169-181

Knapp, A.K., S.L. Conart and J.M. Blair. 1998. Determinants of soil $\mathrm{CO} 2$ flux from a subhumid grassland: effect of fire and fire history. Ecol. Appl. 8:760-770

Koukoura, Z. 1998. Decomposition and nutrient release from C3 and C4 plant litters in a natural grassland. Acta Oecol. 19:115-123.

Koukoura, Z., A.P. Mamolos and K.L. Kalburtji. 2003. Decomposition of dominant plant species litter in a semi-arid grassland. Appl. Soil Ecol. 23:13-23.

Kovach Computing Services 2004. MVSP v3.131.

Loydi, A., T.W. Donath, R.L Eckstein and A. Otte. 2015. Non-native species litter reduces germination and growth of resident forbs and grasses: allelopathic, osmotic or mechanical effects? Biol Invasions 17:581-595.

Mellilo, J.M., J.B. Aber, J.F. Muratore. 1982. Nitrogen and lignin control of hardwood leaf litter decomposition dynamics. Ecology 63:621-626.

Mirek, Z., H. Piękoś-Mirkowa, A. Zając and M. Zając. 2002. Flowering plants and pteridophytes of Poland - a checklist. In Z. Mirek (ed.), Biodiversity of Poland. Vol. 1. Szafer Institute of Botany, Polish Academy of Science, Kraków.

Moretto, A.S., R.A. Distel and N.G. Ditone. 2001. Decomposition and nutrient dynamic of leaf litter and roots from palatable and unpalatable grasses in semi-arid grassland. Appl. Soil Ecol. 18:37-37.

Niedrist, G., E. Tasser, C. Lüth, J. Dalla Via and U. Tappeiner, U. 2009. Plant diversity declines with recent land use changes in European Alps. Plant Ecol. 202:195-210.

Poschlod, P., J.P. Bakker and S. Kahmen. 2005. Changing land use and its impact on biodiversity. Basic Appl. Ecol. 6:93-98.

Pruchniewicz, D. 2017. Abandonment of traditionally managed mesic mountain meadows affects plant species composition and diversity. Basic Appl. Ecol. 20:10-18.

Pruchniewicz, D. and L. Żołnierz. 2014. The influence of environmental factors and management methods on the vegetation of mesic grasslands in a central European mountain range. Flora 209:687-692.

Pruchniewicz, D. and L. Żołnierz. 2017. The influence of Calamagrostis epigejos expansion on the species composition and soil properties of mountain mesic meadows. Acta Soc.Bot. Polon. 86:3516.

Radojević, M. and V.N. Bashkin. 2006. Practical Environmental Analysis. The Royal Society of Chemistry, Cambridge, UK.

Rebele, F. and C. Lehmann. 2001. Biological flora of Central Europe: Calamagrostis epigejos (L.) Roth. Flora 196:325-344.

Ross, D.J., K.R. Tate, P.C.D. Newton and H. Clark. 2002. Decomposability of $\mathrm{C} 3$ and $\mathrm{C} 4$ grass litter sampled under different concentrations of atmospheric carbon dioxide at natural $\mathrm{CO}_{2}$ spring. Plant Soil 240:275-286.

Ruprecht, E., T.W. Donath, A. Otte and R.L. Eckstein. 2008. Chemical effects of a dominant grass on seed germination of four familial pairs of dry grassland species. Seed Sci. Res. 18:239-248.

Sankaran, M. and D.J. Augustine. 2004. Large herbivores suppress decomposer abundance in a semiarid grazing ecosystem. Ecology 85:1052-1061

Somodi, I, K. Virágh and J. Podani. 2008. The effect of the expansion of the clonal grass Calamagrostis epigejos on the species turnover of a semi-arid grassland. Appl. Veg. Sci. 11:187-192.

StatSoft, Inc. 2014. STATISTICA (data analysis software system), version 12. www.statsoft.com.

ter Braak, C.J.F. and P. Šmilauer. 2012. Canoco reference manual and user's guide: software for ordination, version 5.0. Microcomputer Power, Ithaca, USA. 496 pp.

Vellend, M., M.J. Lechowicz and M.J. Waterway. 2000. Germination and establishment of forest sedges (Carex, Cyperaceae): tests for home-site advantage and effects of leaf litter. Amer. J. Bot. $87: 1517-1525$.

Xiong, S. and C. Nilsson. 1999. The effects of plant litter on vegetation: meta-analysis. J. Ecol. 87: 984-994.

Received June 8, 2017 Revised August 5, September 1, 2017 Accepted September 4, 2017 